\title{
Assessment of Technical and Economic Feasibility of Activated Charcoal Removal of Organic Matter from Different Streams of Grey Water Through Study of Adsorption Isotherms
}

\author{
Ababu T. Tiruneh ${ }^{1}$, Amos O. Fadiran $^{2}$, William N. Ndlela ${ }^{1}$, Jonna Heikkilä $^{3}$ \\ ${ }^{1}$ Department of Environmental Health Science, University of Swaziland, Mbabane, Swaziland \\ ${ }^{2}$ Department of Chemistry, University of Swaziland, Kwaluseni, Swaziland \\ ${ }^{3}$ Turku University of Applied Sciences, Turku, Finland \\ Email address: \\ atiruneh@uniswa.sz (A. T. Tiruneh), fadiran@unisw.sz (A. O. Fadiran), wndlela@uniswa.sz (W. N. Ndlela), \\ jonna.heikkila@turkuamk.fi (J. Heikkilä)
}

\section{To cite this article:}

Ababu T. Tiruneh, Amos O. Fadiran, William N. Ndlela, Jonna Heikkilä. Assessment of Technical and Economic Feasibility of Activated Charcoal Removal of Organic Matter from Different Streams of Grey Water Through Study of Adsorption Isotherms. American Journal of Environmental Protection. Vol. 5, No. 3, 2016, pp. 56-64. doi: 10.11648/j.ajep.20160503.13

Received: May 6, 2016; Accepted: May 16, 2016; Published: May 30, 2016

\begin{abstract}
The feasibility of household level treatment of grey water with activated charcoal was performed using laboratory batch adsorption testing on locally available charcoal media. The study results indicated that the potential for removal of organic matter was significantly high for the high $\mathrm{pH}$ cloth wash water compared to the low $\mathrm{pH}$ kitchen wastewater which also contained non-adsorbed organics. The addition of ash considerably improved the removal and projected life length of adsorption media for kitchen wastewater treatment. The adsorption isotherms obtained were all modeled adequately using the Freundlich isotherm while the isotherm shapes display different types of adsorption for the different streams of grey water because of the heterogeneous nature of the adsorbates in grey water. The replacement life length of activated charcoal for single drum household level treatment ranged between 7 and 15 months. For family daily flow rates up to 400 lit/day, the replacement costs of a single drum charcoal per cubic meter of grey water treated were calculated to be below the current tariff levels for acquiring water in cities in Swaziland. A considerable part of the grey water pollutant can be removed through pretreatment by sorption alone such as by filtration through sand or other cheap media before adsorption. For complete household level treatment of grey water, a three-step treatment consisting of sand pre-filtration, activated charcoal adsorption and sand post-filtration are recommended.
\end{abstract}

Keywords: Grey Water Treatment, Activated Charcoal, Water Recycling, Wastewater Treatment, Adsorption Isotherm, Pollutant Removal

\section{Introduction}

Grey water recycling has been practiced worldwide since the 1970 s and is being increasingly considered as feasible option for providing readily available water for reuse at household level while at the same time providing environmental protection and water conservation [1]. The pollutant load, such as the organic matter content of mixed grey water streams, may be comparatively low compared to the wastewater from toilets. However, where the grey water streams are dominated by the less diluted kitchen and wash water, the organic matter content can be quite high. In addition, the biodegradability of the different grey water streams is variable. For example, Edwin et al [2] reported $\mathrm{COD} / \mathrm{BOD}_{5}$ ratio of 8.2 for laundry wash water. Such ratio indicates poor biodegradability of the waste stream. By contrast grey water from the kitchen was reported to have $\mathrm{COD} / \mathrm{BOD}_{5}$ ratio of only 1.2. These kinds of differences in biodegradability of grey water can pause a challenge to the task of treating grey water by biological means. For this 
reason, other treatment alternatives such as activated charcoal adsorption are worthy of consideration for grey water treatment.

Carbon media as an adsorbent has been in use for quite long time. Historical records show that carbon has been used for medical purposes as far back as 1550 BC. Further in 200 $\mathrm{BC}$, carbon in the form of wood char was used to remove disagreeable odour. In 1785, chemists learnt that carbon could remove unwanted contaminants from water. Carbon in activated form was first used as filter medium in the late 1800s [3].

Experiments involving the use of activated charcoal for wastewater treatment indicated significant percentage removal of organic matter and of other pollutants from wastewater. For example, Nansubuga et al [4] reported that, for a wastewater pretreated with activated sludge and subjected further to charcoal filtration, COD removal percentages up to $60 \%$ were achieved. The mechanism of adsorption of organic compounds from grey water onto activated charcoal may in general be due to one or a combination of the three forms of adsorption. These are namely: Physical adsorption driven by the weak London Forces; electro-static interactions; and adsorption resulting from chemical interactions between the adsorbent and the adsorbate. However, the predominantly non-polar nature of organic compounds in grey water may favor the physical type of adsorption due to the lesser polar attraction of the solvent water. Even then, because of the general heterogeneity of the compounds present in grey water, the adsorption mode is expected to be mixed consisting of all the three mechanisms [5].

The adsorption of pollutants on activated carbon is modeled through a number of isotherm models. The Langmuir adsorption model is suited for homogenous, monolayer adsorption [6]. In Langmuir adsorption isotherm models, it is assumed that adsorption is only on local sites whereby the interaction between adjoining adsorbed molecules is limited and the adsorption is represented by a single layer [7]. The adsorption of compounds from grey water containing heterogeneous mix of compounds on activated charcoal may better be represented by the more versatile, though empirical, Freundlich adsorption model which is suited for a mixture of heterogeneous adsorption with multi-layer adsorption capabilities.

The effect of $\mathrm{pH}$ on adsorption depends partly on the level of hydrophobicity of the adsorbate. Hydrophobic organic compounds that are often present in grey water streams are not expected to be influenced by variation in $\mathrm{pH}$. However, for pollutants in grey water that may display some level of polarity, $\mathrm{pH}$ can have a significant influence on the extent of adsorption [8]. The effect of $\mathrm{pH}$ can be considerable particularly for grey water streams containing significant concentrations of organic acids. At low $\mathrm{pH}$ the competing influence of the presence of excess $\mathrm{H}^{+}$ions in the solute can make adsorption of organic acids difficult [9]. On the other hand, the increase in surface acidity of activated carbon as a result of the presence of functional groups such as the carboxylic acid groups on the charcoal media has been implicated in the reduced capacity of activated carbons in attracting and removing hydrophobic compounds [10].

The kinetics of adsorption influences the extent to which equilibrium is reached and whether the equilibrium models can be applicable. The inter-particle diffusion may be the limiting rate especially when fast advective flows occur in adsorption columns. In such situations, the time available for adsorption may not be enough for equilibrium to form as it is constrained by the limited rate of inter particle diffusion. Some studies asserted that even a slow advection velocity as low as $1 \mathrm{~cm} \cdot \mathrm{hr}^{-1}$ may not be enough to attain equilibrium in terms of adsorption [11]. For example, for the modeled flow in this research, the velocity of flow in a single drum activated charcoal treatment is estimated to be around 0.8 $\mathrm{cm} . \mathrm{hr}^{-1}$. This is apparently low advection velocity but not so low as to ensure complete equilibrium [11]. However, this may relate to the theoretical $100 \%$ equilibrium and for most hydrophobic compounds which constitute the grey water components, equilibrium may be reached faster. Because of this, equilibrium models are applied even at much faster velocity of transport of solutes [12]. The assertion that equilibrium is slow to attain serves to illustrate the theoretical limitation of equilibrium adsorption models in terms of the slow kinetics but may not be of great practical significance.

The economic feasibility of household level recycling of grey water through activated charcoal adsorption should consider treatment costs which include both running and capital costs [13]. This cost system depends on the complexity of the grey water system and the extent to which such system is affordable by households concerned. For household level grey water treatment in communities such as Mnyamatsini in Swaziland where the research project was undertaken and in which the majority of the water supply is in the form of yard taps, the installation of pumps may not be considered an appropriate choice. Doing away with pumps also reduces the running cost. The cost system is, therefore, kept simple and consists of cost of components such as the charcoal holding drum, pipe accessories and the replacement cost of the activated charcoal.

The possibility of regeneration of activated charcoal is limited by the energy intensive nature of the recovery. Because of the release of excess energy in the form of heat during the adsorption process, adsorption is considered as exothermic process. By contrast, regeneration, the reverse process, is endothermic and requires external heat energy input for it to take place [14]. The technology of regeneration can be complex with elevated heating as the only technically viable regeneration alternative at household level. However such energy intensive procedure is uneconomical. Regeneration is, therefore, not an economically feasible alternative especially for household level treatment of grey water.

\section{Materials and Methods}

\subsection{Experimental Design}

The experimental design for the research study was based 
on laboratory batch testing of powdered activated charcoal adsorption of organic matter and development of adsorption isotherm for each batch of grey water tested. The technical and cost feasibility of the treatment were also evaluated based on the resulting isotherms developed. Separate streams of grey water from cloth washing and the kitchen were taken for the tests. The effect of $\mathrm{pH}$ on activated charcoal adsorption was evaluated by treating the low $\mathrm{pH}$ kitchen grey water was ash.

For the batch adsorption study, $200 \mathrm{~mL}$ sample volumes of the grey water to be treated were placed in each of a series of beakers. Measured weights of activated charcoal ranging between $1 \mathrm{~g}$ and $100 \mathrm{~g}$ were then added to the beakers and the mixtures were stirred for sufficient period of time. The sample mixtures were then filtered using filter paper and were taken for the COD testing.

Organic matter removal was selected for evaluation of the adsorption efficiency of activated charcoal through Chemical Oxygen Demand testing. Chemical Oxygen Demand (COD) was determined using potassium dichromate oxidation. For the COD test, the closed reflux titrimetric method was followed [15]. For each sample tested for COD before and after treatment with activated charcoal, $2.5 \mathrm{~mL}$ of the sample was pipetted into the digestion tube, followed by addition of $2.5 \mathrm{~mL}$ of potassium dichromate reagent $(0.1 \mathrm{M})$ and $3.5 \mathrm{~mL}$ of sulfuric acid reagent. The digestion tubes were capped, placed into block digester and heated for 2 hours at $150^{\circ} \mathrm{C}$. The digested samples were then cooled and quantitatively transferred to conical flasks after which few drops of ferroin indicator were added. The samples were then titrated with ferrous ammonium sulphate titrant $(0.005 \mathrm{M})$. The COD was then determined using the formula:

$$
\text { COD as } m g \frac{O_{2}}{L}=\frac{(A-B) * M * D * 8000}{m L \text { of sample }}
$$

Where:

$A=$ mL FAS used for blank

$\mathrm{B}=\mathrm{mL}$ of FAS used for sample

$\mathrm{M}=$ molarity of ferrous ammonium sulphate titrant $(0.005 \mathrm{M})$

$\mathrm{D}=$ dilution factor for the sample,i.e., the ratio of volume of sample to total volume of dilution from which the $2.5 \mathrm{~mL}$ sample was taken for digestion.

$8000=$ Milli-equivalent weight of oxygen X $1000 \mathrm{~mL} / \mathrm{L}$

Because of the lack of homogeneity of grey water samples and the small sample size used for digestion, a minimum of three repetitions were made for each of the COD test determined. For the determination of $\mathrm{pH}$ of raw grey water samples as well as treated ones, a $\mathrm{pH}$ meter was used that was periodically calibrated with standard buffers of $\mathrm{pH}=4$, $\mathrm{pH}=7$ and $\mathrm{pH}=10$.

\section{Adsorption isotherms}

For modeling the adsorption isotherms, the Freundlich model has been found fitting in most of the experiments. The Freundlich adsorption model takes the form:

$$
\frac{X}{M}=K C^{\frac{1}{n}}
$$

Where $(\mathrm{X} / \mathrm{M})$ is the pollutant adsorbed per unit mass of charcoal, $\mathrm{C}$ is the pollutant in equilibrium with the adsorbent (COD in $\mathrm{mg} / \mathrm{L}$ ) and $\mathrm{K}$ and $\mathrm{n}$ are constants evaluated from the log-log plot of (X/M) Vs. C.

\subsection{Mass Transfer Model of Adsorption}

The mass transfer model of adsorption [16] is used to model the adsorption onto the activated charcoal using the equation:

$$
\frac{d C}{d h}=\frac{k_{a}}{Q}(C-C *)
$$

The height of the adsorption zone $h_{z}$ is calculated using the equation:

$$
h_{z}=\frac{Q}{K_{a}} \int_{C_{B}}^{C_{E}} \frac{d C}{(C-C *)}
$$

Where $\mathrm{Q}$ is the wastewater flow rate, $\mathrm{K}_{\mathrm{a}}$ is the overall mass transfer coefficient which includes the resistances offered by film and pore diffusion, $\mathrm{C}$ is the COD concentration at particular height $\mathrm{h}<\mathrm{h}_{\mathrm{z}}$ and $\mathrm{C}_{\mathrm{B}}$ and $\mathrm{C}_{\mathrm{E}}$ are the solute $\mathrm{COD}$ concentrations in equilibrium with the adsorbent at breakthrough and exhaustion respectively.

For a given height of adsorption column which is assumed to be $\mathrm{H}=0.6 \mathrm{~m}$ and for a single drum household level charcoal treatment with drum diameter of $0.572 \mathrm{~m}$ and flow rate of 50 lit/day, the mass transfer coefficient $\mathrm{K}_{\mathrm{a}}$ is computed from the following equation [17]:

$$
K_{a}=\frac{G}{H} \int_{C_{B}}^{C_{E}} \frac{d C}{(C-C *)}
$$

Where $G$ is the mass flow rate of the wastewater in $\mathrm{Kg} / \mathrm{min}-\mathrm{m}^{2}, \mathrm{H}$ is the depth of the adsorption column (m) and the integral expression is as defined above.

It will be noted in the subsequent presentation and discussion of the research results that the mass transfer rate calculated is low due to the low flow rate adopted and this low rate of mass transfer results in low value of the adsorption zone, $h_{z}$. The low value of adsorption height $h_{z}$ is useful for complete utilization of the available depth of the media.

The fractional capacity of the adsorption zone in the phase between breakthrough and exhaustion is calculated using the equation:

$$
F=\int_{0}^{1}\left(1-\frac{C}{C_{0}}\right) \Delta\left(\frac{V-V_{B}}{V_{E}-V_{B}}\right)
$$

Where $\mathrm{F}$ is the fraction of adsorption zone available for adsorption, $\mathrm{C}_{0}$ and $\mathrm{C}$ are the $\mathrm{COD}$ concentrations before and after adsorption respectively and $\mathrm{V}, \mathrm{V}_{\mathrm{B}}$ and $\mathrm{V}_{\mathrm{E}}$ are the volume of wastewater treated at current fractional capacity, at break through and exhaustion respectively.

For calculation of the ultimate capacity of the activated charcoal, the percentage saturation is calculated from the equation;

$$
\% \text { saturartion }=\frac{H+(F-1) h_{z}}{H} * 100
$$


Where $\mathrm{H}$ is the depth of the activated charcoal, $\mathrm{F}$ is the fractional capacity and $h_{z}$ is the depth of the adsorption zone. This equation has been used to calculate the length of run of the activated charcoal design as will be shown later.

\section{Results and Discussion}

\subsection{Characteristics of the Wastewater Samples Tested}

Different streams of grey water samples were taken for the study and their characteristics in terms of $\mathrm{pH}$ and COD were evaluated and are presented in Table 1. The grey water samples were taken from two different households and separate samples were taken from each house representing wastewater samples from the kitchen and wash water from cloth washing. The wastewater sample from one of the kitchens was further modified with the addition of ash with a view to increasing the $\mathrm{pH}$ of the sample. According to the results shown in Table 1, grey water samples from kitchen and cloth washing all have higher organic strength as are evidenced by the high COD values of all the samples. Comparison of grey water samples from kitchen and cloth washing also shows that grey water samples from the kitchen have relatively higher organic strength while their $\mathrm{pH}$ is low. The low $\mathrm{pH}$ is expected due to the formation of organic acids during the initial storage time of the more biodegradable kitchen water samples. By contrast, grey water samples from cloth washing have relative higher $\mathrm{pH}$ ranging between 8 and 9.5. As will be shown later, the adsorption of organics by activated charcoal shows a bias in favour of better adsorption at higher $\mathrm{pH}$. This fact motivated the modification of one of the grey water samples from kitchen with readily available ash.

Another important observation revealed through the study is the ease with which significant portion of the organic matter in both the kitchen and cloth washing samples were removed by filtration prior to adsorption by activated charcoal. All the samples were filtered through \#100 filter paper and the CODs of the raw water and filtered water samples were analyzed.

Table 1 again shows the percentage removal of organics by filtration. Organic matter from cloth washing, measured as COD, was easily be removed $60-70 \%$ by sorption alone while for kitchen grey water the percentage COD removal ranged between 36 and $70 \%$.

Table 1. Characteristics of the grey water samples tested for charcoal adsorption.

\begin{tabular}{|c|c|c|c|c|}
\hline \multirow{2}{*}{ Waste water type } & pH range & Initial COD & Filtered COD & Percentage removal by sorption \\
\hline & (pH units) & $\mathrm{mg} / \mathrm{L}$ & $\mathrm{mg} / \mathrm{L}$ & $(\%)$ \\
\hline Cloth wash water-1 & $8.00-9.25$ & 1800 & 714 & $60 \%$ \\
\hline Cloth wash water-2 & $8.31-9.5$ & 2630 & 770 & $70 \%$ \\
\hline Kitchen wastewater-1 & $3-68-5.00$ & 2320 & 1470 & $36 \%$ \\
\hline Kitchen wastewater-2 & $4.00-4.38$ & 2740 & 830 & $70 \%$ \\
\hline Kitchen wastewater + ash & $8.03-8.52$ & 2000 & 867 & $56 \%$ \\
\hline
\end{tabular}

Since there is no significant chemistry involved in removal of organic matter by filtration, the removal can only conceivably considered to be sorption. This finding is useful for activated charcoal adsorption as it is recommended to provide filtration as pretreatment prior to charcoal adsorption since the activated charcoal adsorption is best reserved for adsorption of soluble organics

\subsection{Adsorption Characteristics Among Different Wastewater Streams}

For each stream of grey water tested, the organic matter adsorbed per unit weight of charcoal adsorbent $(\mathrm{X} / \mathrm{M})$ was plotted against the grey water solute COD (C) that is in equilibrium with the adsorbent. Figures, 1, 2 and 3 show the different nature of the adsorption isotherms obtained from the test results. As is evident from Figure 1, grey water from cloth washing was amenable to complete adsorption as the isotherm curves tend to pass through the origin as the mass of the adsorbent increases. By contrast for grey water from the kitchen (Figure 2), the adsorption curves do not pass through the origin. It can be seen from Figure 2 that the curves intersect the COD line at around $500 \mathrm{mg} / \mathrm{L}$ which represents the non-adsorbable part of COD. Modification of the samples through the addition of ash to a certain extent decreased the non-adsorbed COD from 500 to about $400 \mathrm{mg} / \mathrm{L}$.

The adsorption curves also vary between the Type I $(n<1)$ and Type III $(n>1)$ curves and show mixed nature of adsorption of the grey water sample tested. This mixed nature of adsorption may be expected considering the heterogeneous nature of constituents of grey water. The convex downward adsorption isotherm of wash water shown in Figure 1 with $(1 / \mathrm{n})<1$ in the adsorption isotherm is typical of cases where the marginal adsorption energy decreases with increasing surface concentration [18]. By contrast the rest of the curves in Figures 1 and 2 have $(1 / \mathrm{n})>1$ with the Freundlich isotherm model. This isotherm is typical of cases where the marginal adsorption energy increases with increasing surface concentration [19]. It may represent a result of strong intermolecular forces in the adsorbent layer and penetration of the solute further in the adsorbent media. Part of the difference in the nature off adsorption shown in Figure 1 and Figure 2 between $(1 / n)<1$ and $(1 / n)>1$ may be explained by the solute COD concentrations whereby the higher solute organic compound concentrations influence intermolecular forces resulting in increase in the marginal energy of adsorption at higher surface concentration of adsorbed 
compounds. This cooperative adsorption may become dominant in situations where the activated charcoal surface, possessing increased surface acidity and preventing adsorption of non- polar organics is covered and facilitates further adsorption through cooperative adsorption mechanism [20].

However, the adsorption for cloth wash water-1 shown in Figure 1 with $(1 / \mathrm{n}=0.612)<1$ has its $(1 / \mathrm{n})$ sufficiently lower than the $n=1$ linear adsorption range. Thus the adsorption is influenced by decreasing surface energy of adsorption which happens at higher solute COD values typical of grey water streams. In short the adsorption is different from the linear adsorption isotherm that usually happens at low solute COD concentrations such as in natural non-point source pollutions from runoff [21].

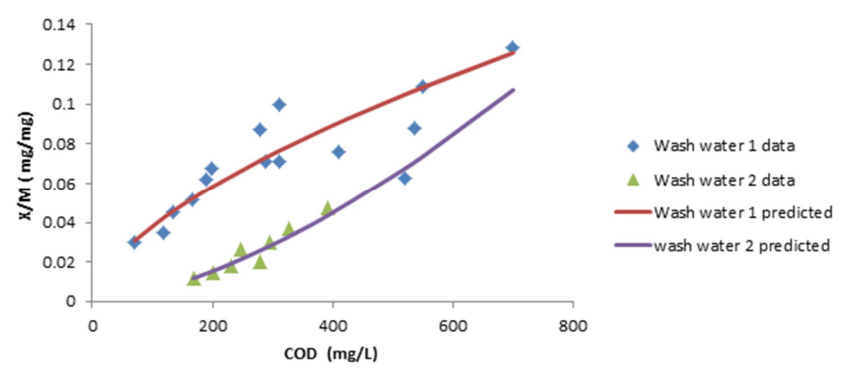

Figure 1. Mixed nature of the adsorption isotherm of grey wash water from cloth washing.

The comparison of the adsorption efficiency between grey water samples from cloth washing and the kitchen as shown in Figure 3 indicates that generally grey water from cloth washing show greater efficacy of adsorption compared with grey water samples from the kitchen. The efficiency of adsorption of the kitchen grey water samples was increased by about $30 \%$ when these samples were modified with the addition of ash to increase the $\mathrm{pH}$ environment of the adsorption. This step was motivated by the apparent difference in extent of adsorption at high $\mathrm{pH}$ environment of the cloth water samples. The decrease in adsorption of organics at low $\mathrm{pH}$ may be explained possibly because of the competing influence of the presence of excess $\mathrm{H}^{+}$at low $\mathrm{pH}$ competing for adsorption with the organic acids present in kitchen wastewater [9].

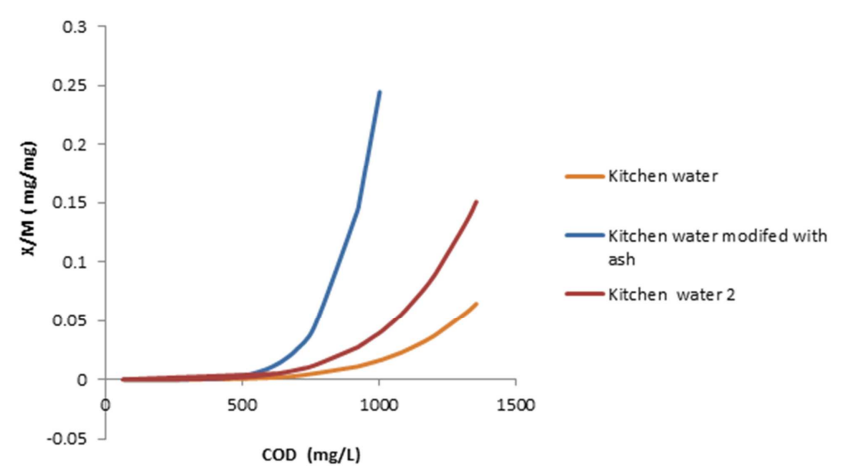

Figure 2. Comparison of isotherms of grey water from kitchen including the effect of adding ash.

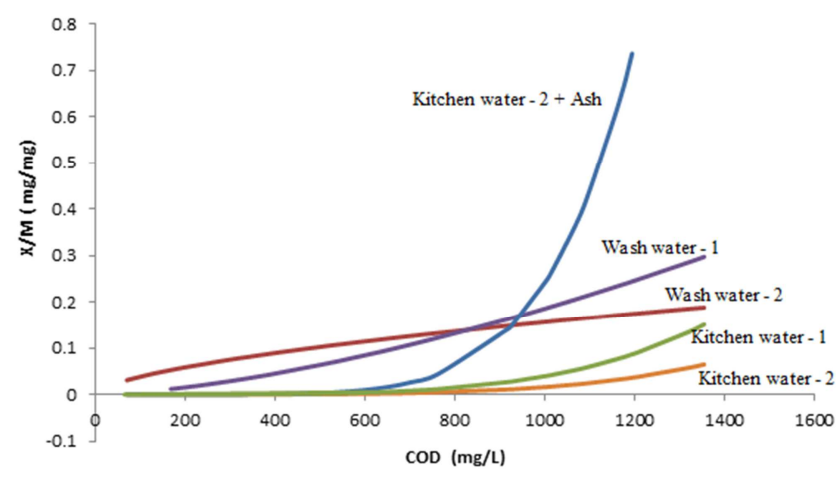

Figure 3. Comparison of isotherms of different streams of grey water.

Apart from the mixed nature of the adsorption, the test results shown in Figure 2 illustrate the difficulty of adsorption of some streams of kitchen water with activated charcoal. This indicates that not all streams of grey water are adsorbed to a favorable degree by activated charcoal.

\subsection{Development of Adsorption Isotherms}

The adsorption isotherms for all the grey water samples tested were found to be adequately modeled through the Freundlich adsorption model. The model constants $\mathrm{K}$ and $\mathrm{n}$ were determined by regression of the logarithm of $(\mathrm{X} / \mathrm{M})$ against logarithm of COD values in equilibrium with the adsorbent ( $\mathrm{C}$ value). Figures 4 and 5 show the regression plot of the Freundlich isotherm for typical cloth washing and kitchen grey water samples.

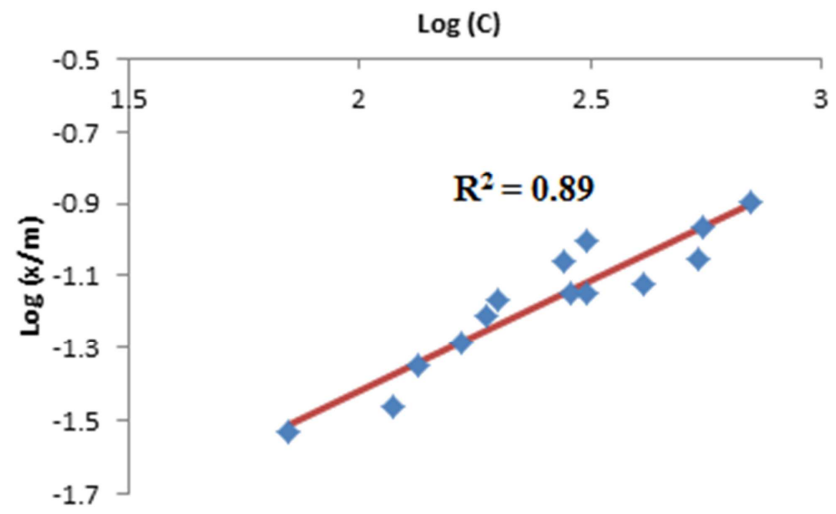

Figure 4. Freundlich isotherm of activated charcoal adsorption of cloth wash water -1 .

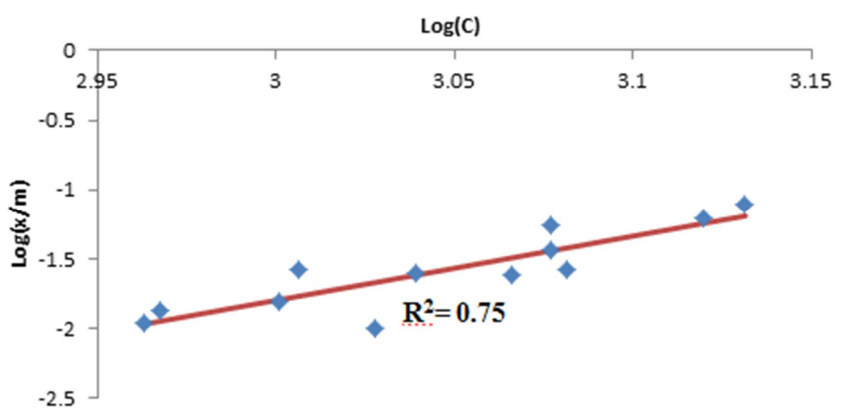

Figure 5. Freundlich isotherm of activated charcoal adsorption kitchen wastewater-2. 


\subsection{Operation Lines and Fractional Capacities}

Assuming that saturation adsorption zone moves uniformly through the adsorption column the operation lines and equilibrium lines for the different grey water streams are plotted and shown in Figures 6 and 7. It can be seen from Figure 6 that the lines are close for the cloth wash water whereas Figure 7 shows that a marked variation in the operation lines for the different grey water streams. Modification of the second grey water sample from kitchen with ash is seen to improve the operation lines considerably. This improvement shows also in the marked increase in the length of operation of the adsorption column as calculated from the isotherm models.

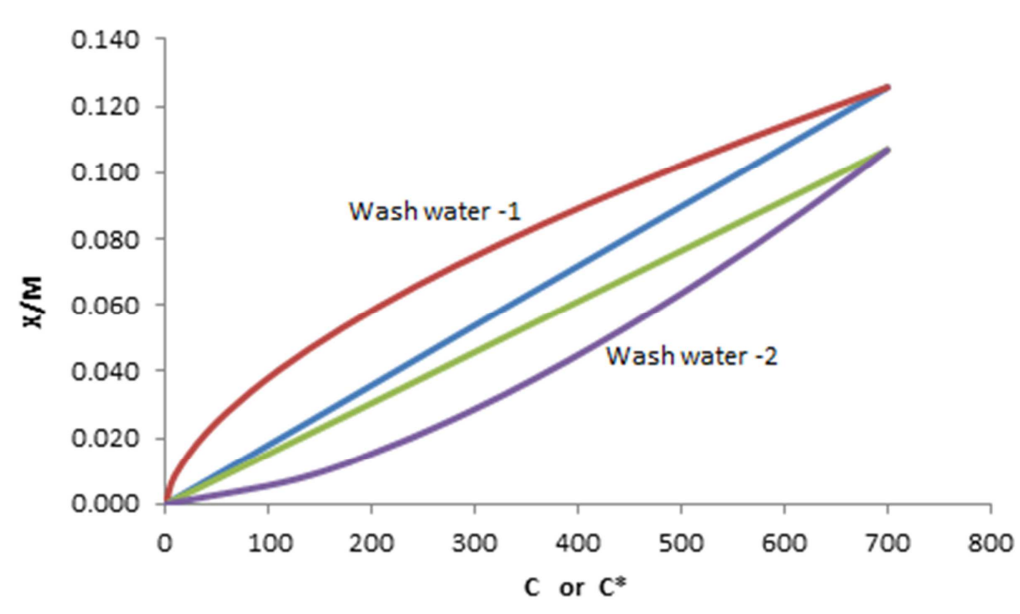

Figure 6. Operation lines of grey water from cloth washing.

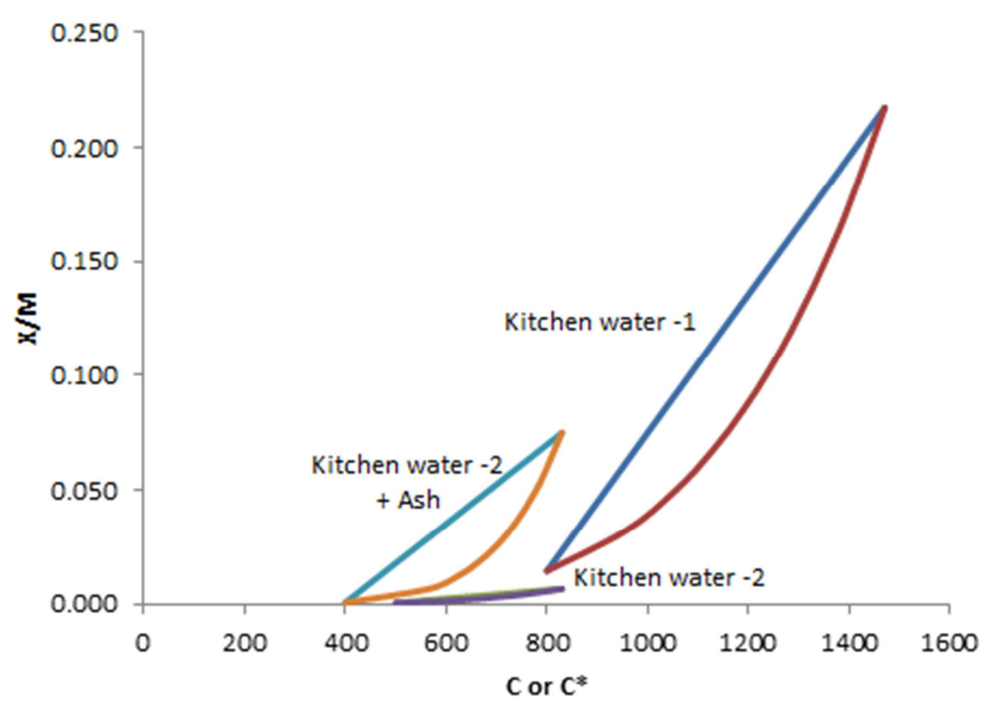

Figure 7. Operation line of grey water from kitchen including ash modification.

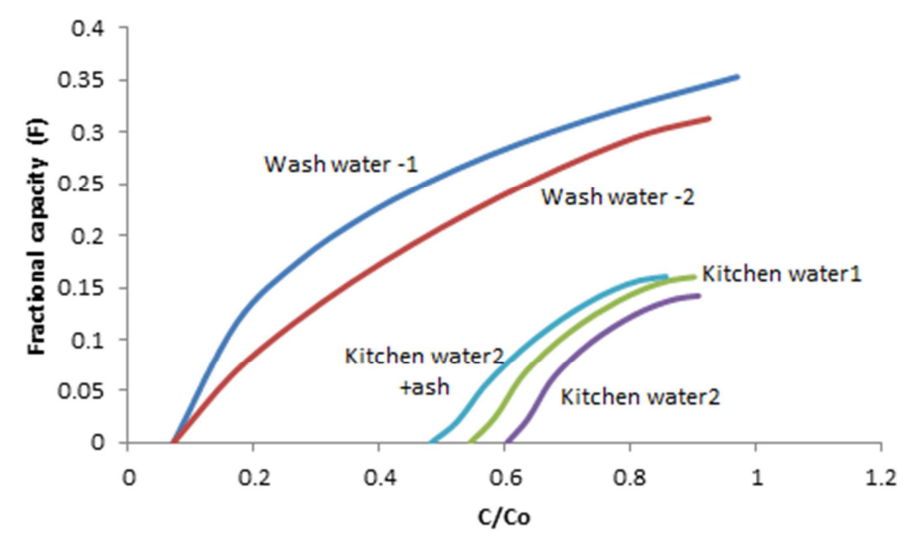

Figure 8. Fractional capacity at breakthrough for the different streams of grey water. 
The fractional capacities of the different stream of grey water are shown in Figure 8. The differences in the available fraction of adsorption column within the adsorption zone between the different streams of grey water are apparent from Figure 8 . The calculation of percentage saturation of the adsorption zone for a $60 \mathrm{~cm}$ depth of charcoal in a single drum when breakthrough occurs was worked out and is shown in Table 2. In all cases, the percentage saturation is very high and it can be safely stated that most the charcoal will be utilized for adsorption at breakthrough and this fact can be taken into consideration for the subsequent computation of the length of life of the drum of charcoal and the running cost per cubic meter of wastewater treated as shown below.

Table 2. Percentage saturation of the adsorption zone at column breakthrough.

\begin{tabular}{|c|c|c|c|c|c|c|c|c|c|}
\hline Type of grey water & $\begin{array}{l}\text { drum } \\
\text { diameter }\end{array}$ & $\begin{array}{l}\text { Depth of } \\
\text { charcoal }\end{array}$ & Area & Flow rate & $\begin{array}{l}\text { Flow rate } \\
\text { (Q) }\end{array}$ & $\begin{array}{l}\text { Mass } \\
\text { transfer, } K_{a}\end{array}$ & $\begin{array}{l}\text { Fractional } \\
\text { capacity }\end{array}$ & $\begin{array}{l}\text { Depth of } \\
\text { adsorption zone }\end{array}$ & $\begin{array}{l}(\%) \\
\text { saturation }\end{array}$ \\
\hline & $(\mathrm{m})$ & (m) & $\left(\mathrm{m}^{2}\right)$ & (lit/day) & $\left(\right.$ lit/min-m $\left.{ }^{2}\right)$ & $\mathrm{Kg} /\left(\mathrm{min}-\mathrm{m}^{3}\right)$ & & (m) & \\
\hline Wash water-1 & 0.572 & 0.6 & 0.257 & 50 & 0.009 & 2.145 & 0.353 & 0.03962 & 95.73 \\
\hline Wash water-2 & 0.572 & 0.6 & 0.257 & 50 & 0.009 & 2.044 & 0.313 & 0.03962 & 95.46 \\
\hline Kitchen water-1 & 0.572 & 0.6 & 0.257 & 50 & 0.009 & 0.914 & 0.16 & 0.03962 & 94.45 \\
\hline Kitchen water-2 & 0.572 & 0.6 & 0.257 & 50 & 0.009 & 0.989 & 0.142 & 0.03962 & 94.33 \\
\hline Kitchen water $2+$ ash & 0.572 & 0.6 & 0.257 & 50 & 0.009 & 0.513 & 0.16 & 0.03962 & 94.46 \\
\hline
\end{tabular}

\subsection{Economic Feasibility of Using Charcoal Adsorption for Grey Water Treatment}

The hypothetical replacement cost for a single drum of charcoal with depth $60 \mathrm{~cm}$ and diameter of $57.2 \mathrm{~cm}$ for treating a typical daily grey wastewater of 50 lit/day from a household was worked out for the different streams of grey water using the adsorption modeling information presented earlier. The result is summarized in Table 3. It can be seen from Table 3 that, barring the second kitchen water sample, most of the grey water samples studied show a longer run length for a single drum treatment ranging between 7.2 and 15.1 months. The single drum charcoal life length for the difficult to treat stream of kitchen wastewater was also extended from 1 month to 8.1 months which is a very significant improvement. The replacement cost in the feasible cases is below the current baseline tariff provided by the Swaziland Water Services Corporation of about $3 \mathrm{USD} / \mathrm{m}^{3}$ of water. This comparison, however, is tentative as there are several other running costs involved in treating grey water.

The variation with daily flow rate of the length of life of activated charcoal and its replacement cost per cubic meter of water treated are given in Figure 9 and Figure 10 respectively. Comparing the costs with the current tariff of acquiring one cubic meter of water in the city which is about 3 USD, it can be seen from Figure 10 that the single drum charcoal can run economically up to a daily flow rate of 400 lit/day. The corresponding economical length of life as seen from Figure 9 can be as low as 0.5 months. This means that replacing the charcoal even every two seeks is economically justifiable compared with the per cubic meter cost of acquiring water from the city water supply.

Post treatment of the grey water stream from the kitchen following activated charcoal adsorption is necessary because of the significant proportion of non-adsorbed organics from the kitchen wastewater streams. It is, therefore, generally recommended that a post-adsorption sand filter drums be provided to remove the remaining organics further by anaerobic/aerobic biological means. The suitable recommended pilot combination of treatment for household grey water streams would, therefore consist of drums of coarse sand filter acting as pretreatment by sorption, followed by activated charcoal adsorption and finally drums of fine sand filter for removal of the residual soluble organics by a combination of /anaerobic treatment.

The study results presented above give a useful insight into the technical and economic feasibility of treating grey water using activated charcoal as well as forming a design basis for further pilot scale study of treatment with the mentioned combination of sand filters and activated charcoal adsorption.

The spent charcoal cannot be regenerated economically and may either be disposed off or possibly be burnt to generate energy for the household. However, the health impact of burning spent charcoal which contains potentially harmful substances adsorbed from grey water need to be taken into consideration before choosing such alternative.

Table 3. Cost of Length of run of charcoal with replacement cost for different types of grey water.

\begin{tabular}{llllllllll}
\hline \multirow{2}{*}{ Type of grey water } & $\begin{array}{l}\text { Initial } \\
\text { COD }\end{array}$ & $\begin{array}{l}\text { Effluent } \\
\text { COD }\end{array}$ & $\begin{array}{l}\text { COD } \\
\text { removal }\end{array}$ & (X/M)sat & $\begin{array}{l}\text { Mass of } \\
\text { charcoal }\end{array}$ & $\begin{array}{l}\text { COD } \\
\text { adsorbed }\end{array}$ & $\begin{array}{l}\text { Waste water } \\
\text { flow rate }\end{array}$ & $\begin{array}{l}\text { Run time } \\
\text { Replacement } \\
\text { cost }\end{array}$ \\
\cline { 2 - 10 } & $\mathbf{m g} / \mathbf{L}$ & $\mathbf{m g} / \mathbf{L}$ & $\mathbf{( \% )}$ & & $\mathbf{( K g )}$ & $\mathbf{( K g )}$ & (lit/day) & (Month) & (USD per $\mathbf{m}^{3}$ ) \\
\hline Wash water-1 & 700 & 50 & $93 \%$ & 0.126 & 74 & 8.901 & 50 & 8.5 & 2.3 \\
Wash water-2 & 700 & 50 & $93 \%$ & 0.107 & 74 & 7.553 & 50 & 7.2 & 2.7 \\
Kitchen water-1 & 1400 & 500 & $64 \%$ & 0.217 & 74 & 15.194 & 50 & 15.1 & 1.3 \\
Kitchen water-2 & 830 & 500 & $40 \%$ & 0.007 & 74 & 0.474 & 50 & 1.0 & 20.6 \\
Kitchen water -2 + Ash & 830 & 400 & $52 \%$ & 0.075 & 74 & 5.246 & 50 & 8.1 & 2.4 \\
\hline
\end{tabular}




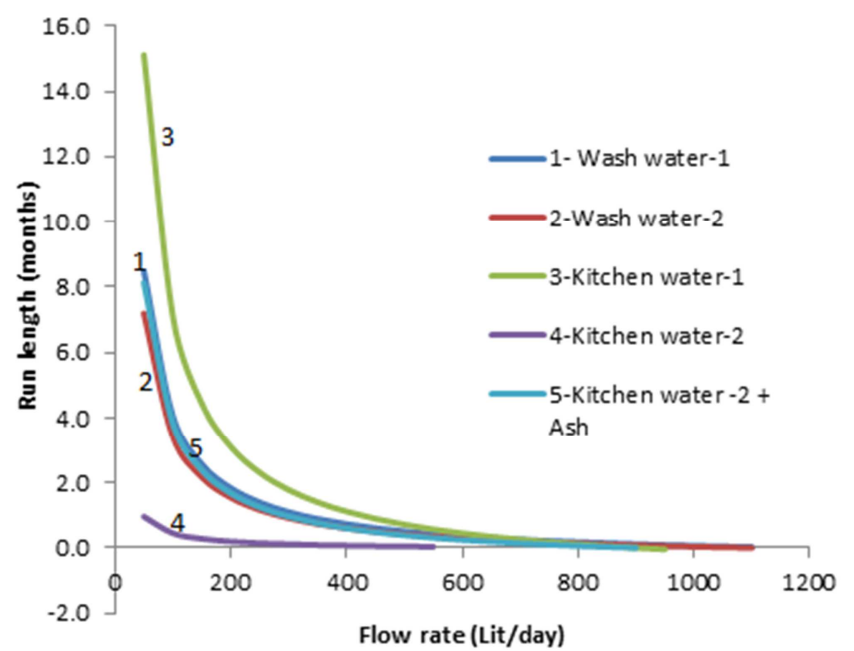

Figure 9. Length of run of a single drum of charcoal at different daily flow rates.

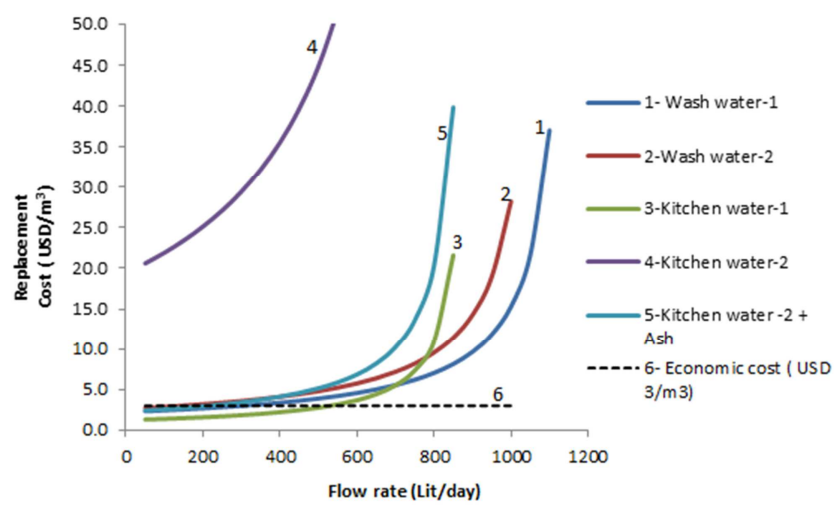

Figure 10. Cost comparison of replacement cost of charcoal at different daily flow rates.

\section{Conclusion}

Adsorption of organics from grey water streams using activated charcoal at household level provides a feasible treatment alternative. The research study indicated that activated charcoal can remove over $95 \%$ of the organic matter from cloth wash water while the efficiency of removal of organics from kitchen wastewater ranges between 30 and $70 \%$. The efficiency of removal of organic matter using activated charcoal adsorption is seen to increase with increase $\mathrm{pH}$ as grey water with higher $\mathrm{pH}$ are removed more easily than the low $\mathrm{pH}$ kitchen wastewater. In addition modification of kitchen wastewater $\mathrm{pH}$ through the addition of ash improves the performance and considerably extends the life length of charcoal columns to economical ranges.

The adsorption isotherms display a mixed isotherm ranging between Type I and Type III adsorption which is typical as grey water represents a heterogeneous mixture of different organic compounds. The adsorption isotherm of cloth wash water passes through the origin were as the ones for kitchen wastewater intersect the COD axis at considerable COD values which represents the non-adsorbed part of the organic matter from kitchen waste streams.
It has also been seen that a considerable portion of the organics from the different grey water stream scan be removed by the physical process of sorption alone. Any type of media that presents a filtration mechanism including readily available sand can be employed for this sorption process. Such pretreatment is useful prior to activated charcoal adsorption as the adsorption is best reserved for the soluble part of the organic matter.

For mixed grey water streams that may be containing a combination of wash water and kitchen water, it is recommended to have a three step treatment consisting of a pretreatment coarse sand filter drum followed by drums of activated charcoal adsorption and finally sand filter drums for anaerobic/aerobic treatment of the residual organics following adsorption by activated charcoal.

Calculation of the length of life of a single drum of activated charcoal for household level treatment of a 50 lit/day grey water stream for the different types of grey water shows that the single drum can serve for a period ranging from 7 to 15 months depending on the type of grey water. Modification of the difficult to treat kitchen wastewater streams with ash also significantly improves the life length of a single drum from a non-feasible one month to almost eight months. In addition the economic life length of the charcoal can be as low as half a month while at the same time keeping the per cubic meter cost charcoal replacement below the tariff need to acquire the same volume of water from the city supply. In addition, a daily wastewater flow of up to 400 lit/day can be economically treated by a single drum activated charcoal treatment.

Comparison of the replacement cost of the charcoal at the current market cost indicates that the per-cubic replacement cost is below the current tariff levels of a unit cubic meter of water in cities in Swaziland. In general, the study indicated that activated charcoal represents a potentially feasible treatment alternative for the household level treatment of grey water.

\section{Acknowledgment}

This research study was supported by the government of Finland as part of the Mbabane Dry Sanitation and Waste Management Project (MDSWMP) research activity. The researchers would like to thank the financial assistance provided for carrying out the research work.

\section{References}

[1] Pidou MA, Memmon FA, Stephenson T, Jefferson B, Jeffrey P (2007). Grey water recycling: A review of treatment options and applications. Engineering Sustainability, 160: 119-131.

[2] Edwin GA, Gopalsamy P, and Muthu N (2014) Characterization of domestic gray water from point source to determine the potential for urban residential reuse: a short review. Appl Water Sci. 4: 39-49. 
[3] USACE: Us Army Corps of Engineers (2001) Adsorption design guide. Design Guide No. 1110-1-2.

[4] Nansubuga I, Meerburg F, Banadda, N, Rabaey K, Verstrete W (2015). A two stage decentralized system combining high rate activated sludge with alternating charcoal filters for treating small community sewage to reusable standards in agriculture. African journal of Biotechnology Vol (14) 7, pp. 593-603.

[5] Thomas CV, Walter J, Weber JR (1983) Sorption of hydrophobic compounds by sediments, soils and suspended solids - theory and background. Water Res. Vol. 17, No. 10, pp. 1433-1441.

[6] Nethaji S, Sivasamy A, Mandal, AB (2013) Adsorption isotherms, kinetics and mechanism for the adsorption of cationic and anionic dyes onto carbonaceous particles prepared from Juglans regia shell biomass. Int. J. Environ. Sci. Technol. 10:231-242.

[7] Site AD (2001) Factors Affecting Sorption of Organic Compounds in Natural Sorbent Water Systems and Sorption Coefficients for Selected Pollutants: A Review. Phys. Chem. Ref. Data, Vol. 30, No. 1

[8] Harris CI and Warren GF (1964) Adsorption and desorption of herbicides by soil. Weeds 12: 120-126.

[9] El-Khaiary MI, Hameed BH (2008) Malachite green adsorption by rattan sawdust: Isotherm, kinetic and mechanism modeling. J Hazard Mater 159:574-579.

[10] Li QL, Snoeyink VL, Mariaas BJ, Campos C (2003) Elucidating competitive adsorption mechanisms of atrazine and NOM using model compounds. Water Res. 37(4): 773784.

[11] Brusseau ML, Larsen T and Christensen TH (1991) Ratelimited sorption and non-equilibrium transport of organic chemicals in low organic carbon aquifer materials. Water Resour. Res. 27, 1137.
[12] Picer N, Picer M, Strohal P (1977) The interaction of DDT with suspended particles in sea water. Water, Air, Soil Pollut. 8: 429-440.

[13] Hernandeza OR (2004). To treat or not to treat? Applying chemical engineering tools and a life cycle approach to assessing the level of sustainability of a clean-up technology. Green Chem., 6: 395-400.

[14] Flagan J, Richard C. and Seinfeld John H (1988) Fundamentals of air pollution engineering. Prentice-Hall Inc., Englewood Cliffs, New Jersey ISBN 0-13-332537-7, pp. 479520 .

[15] APHA (1999) Standard Methods for the examination of Water and Wastewater: Chemical Oxygen Demand, 5220, \# (102). American Public Health Association, American Water Works Association, Water Environment Federation.

[16] Weber WJ. Jr (1972) Physicochemical processes for water quality control, Wiley-Interscience, New York. 640 pp.

[17] Klobucar JM, Pilat MJ (1992). Continuous flow thermal decomposition of VOC's from activated carbon. Environmental progress 11(1): 11-17.

[18] Farrell J, Reinhard M (1994) Desorption of halogenated organics from model solids, sediments, and soil under unsaturated conditions. Environ. Sci. Technol 28 (1): 53-62.

[19] Haque R. and Coshow WR (1971) Adsorption of isocil and bromacil from aqueous solution onto some mineral surfaces. Environmental Science and Technology 197; 5(2): 139-141.

[20] Pignatello JJ (2000) The measurement and interpretation of sorption and desorption rates for organic compounds in soil media. Adv. Agron. 69: 1-73.

[21] Rao PSC, Davidson JM (1979) Adsorption and movement of selected pesticides at high concentrations in soils. Water Res., 13: 375-380. 